\title{
Political transformation and research methodology in doctoral education
}

\author{
Chaya Herman
}

(C) Springer Science+Business Media B.V. 2009

\begin{abstract}
This paper examines the relationship between political change and epistemologies and methodologies employed at doctorate level. It does so by analysing the range of topics, questions and methodologies used by doctoral students at the University of Pretoria's Faculty of Education between 1985 and 2005-a time-frame that covers the decade before and the decade after South Africa's historical transition to democracy in 1994. During this period the composition of doctoral students at that faculty changed from being largely white and male to a more diverse population in terms of gender and race. A crucial shift took place after 2000 with the arrival of a Black dean who sought to introduce a transformational shift. The paper makes use of Karmon's notion of epistemic environment, which refers to the way knowledge is conceptualised at institutional level. The data shows how the authoritarian and regulated epistemic environment that shaped the conception of knowledge at the faculty until 2000 created doctoral dissertations that aimed to correct and guide the society but lacked critical discourse and relevance to South Africa's political, social and educational context. While the transition to democracy in 1994 produced merely semantic changes, if any, the strong internal initiative to change the research culture from 2000 onwards has managed to shift basic notions of truth and knowledge and the understanding of the role and nature of research. This movement was, however, constrained by the institution's long-established epistemic environment.
\end{abstract}

Keywords Doctoral education - Political transformation - Epistemic environment . Transforming knowledge

The PhD theses on the library shelves bear traces of the setting in which their author lives and worked-biographical, familial, institutional, cultural, historical, political and geographical. What is possible for the individual researchers to ask, the methods with which it is possible for them to inquire, and the templates for what counts as 'academic' vary over time, between and within institutions (Middleton 2001, p. 13).

C. Herman $(\bowtie)$

University of Pretoria, Pretoria, South Africa

e-mail: chaya.herman@up.ac.za 


\section{Introduction}

A comprehensive policy agenda for higher education after 1994 provided South Africa with the framework to overcome its past and to create a more socially equitable and democratic system. This had a significant impact on previously conservative white Afrikaans-medium universities whose intellectual discourse, knowledge production and research were strongly affected by their role as a guardian of the apartheid regime. This paper examines the relationship between political change and knowledge production at doctorate level at one such institution. It does so by analysing the range of topics, questions, research approaches and methodologies used by doctoral students in education at the University of Pretoria's (UP) Faculty of Education over the period 1985-2005. This timeframe is significant as it covers the decades before and after South Africa's historical transition to democracy in 1994.

During this period the doctoral students' cohort has changed from being exclusively white Afrikaner and mostly male, to a more diverse population in terms of gender and race. More significantly, though, from 2000 the education faculty at this conservative Afrikaans institution was for the first time led by a Black dean who sought to bring transformational change to the culture of the faculty (Jansen 2005).

The study aims to investigate to what extent these different political and institutional contexts were evident in the content, epistemologies and methodologies used by the doctoral students, and what impact they have had on the conception of knowledge at doctorate level at this institution.

\section{Methodology}

The paper is based on a systematic review of abstracts of the doctoral dissertations that were awarded at UP's Faculty of Education from 1985 to the present. This is done in fiveyear intervals, that is, 1985, 1990, 1995, 2000 and 2005. The abstracts of 66 of the 67 dissertations awarded in these years were analysed. The comprehensive review is supplemented by selected chapters from the dissertations as well as interviews with graduates and academics at the institution. The paper underscores the use of buzz words and their role in providing the frame of reference for interpreting the world (Cornwall and Brock 2005).

It is evident that the use of sampling to determine trends and the use of abstracts as the main data source pose some limitations on the analysis. Furthermore, as a non-Afrikaans speaker my access to people, documents and the politics of the institution had certain limitations. Since the early dissertations are in Afrikaans, I had to rely on the English abstracts provided by the authors who themselves might not have been fluent in English. Occasionally I used the services of an Afrikaans-English translator.

\section{Conceptual framework}

While the broader transformation in South Africa created the conditions for institutional change in higher education, it is evident that substantive change could only take place at an institutional level provided that there were the capacity and the incentives to do so (Muller 2003; Badat 2008). Yet it is evident that in South Africa the institutional cultures of universities ... still bear their distinctive racial birthmarks expressed in dominant 
traditions, symbols and patterns of behaviour' (Jansen et al. 2007, p. 157). This paper focuses on the relationship between knowledge production at doctorate level and the culture of the institution, in particular the understanding by the members of the institution of the relationship between knowledge and authority, 'about who possesses knowledge to act on and against others, and who are positioned simply as the recipients of authoritative knowledge' (Jansen 2009, p. 172).

In order to conceptualise the relationship between knowledge and authority, this paper makes use of Karmon's (2007) notion of epistemic environment, which refers to the way knowledge is organised at institutional level. Every epistemic environment shapes the conception of knowledge that can be accommodated in that institution:

This environment is saturated with both overt and covert messages, incentives for certain ways of acting and thinking, obstacles that tend to block other approaches, and a typical language. In a structured environment such as this, we are sure to find agents that act in different ways, but this environment tends to lead those within it towards a dominant way of acting and thinking, which is consistent with its main messages, incentives and obstacles (Karmon 2007, p. 609).

This paper traces the shifting conception of knowledge at doctorate level and explores how it links to the changing political and social positioning of the institution. It shows how the authoritarian and regulated epistemic environment that shaped the conception of knowledge at the faculty until 2000 created doctoral dissertations that lacked critical discourse and relevance to the political, social and educational context in South Africa. The paper also demonstrates the extent to which a strong initiative to change this tradition was limited by past understandings of knowledge. The paper begins by providing a quantitative analysis of the education doctorates awarded at UP between 1985 and 2005 and then offers a detailed analysis of the epistemic environments and the knowledge that was produced at doctoral level at different points of this historical and current analysis.

\section{The doctorate in education at the University of Pretoria, 1985-2006}

UP's Faculty of Education awarded 333 doctoral degrees (mostly PhD and some D ED) between 1985 and 2006. This figure comprises about $70 \%$ of all doctorates in education awarded at UP since 1933. Figure 1 indicates the uneven growth in these years, whereby a high number of degrees were awarded in the beginning of the 1990s (86\% growth), with a sharp decline after 1994. It is possible that this large number of doctorates reflects market response to the South Africa Post-Secondary Education (SAPSE) funding formula of 1982, which multiplied by four the subsidy for students at a doctorate level, and encouraged universities to increase enrolment in the cheaper humanities subjects (Bunting 2002a). Further, at least half of these doctorates were supervised by three professors. The sharp decline in the number of doctorates awarded after 1995 might be attributed to their retirement.

Doctoral graduates at UP have changed over time from being predominantly male in 1985 to predominantly female in 2005 (Fig. 2). Furthermore, there has been a convergence over time in the number of black $^{1}$ and white graduates (Fig. 3) -all graduates in 1985 were white. ${ }^{2}$

\footnotetext{
1 Black in this paper is used to denote African, Coloured and Indian graduates.

2 A further study is under way to correlate the shift in gender and race to the different departments within the Faculty of Education.
} 


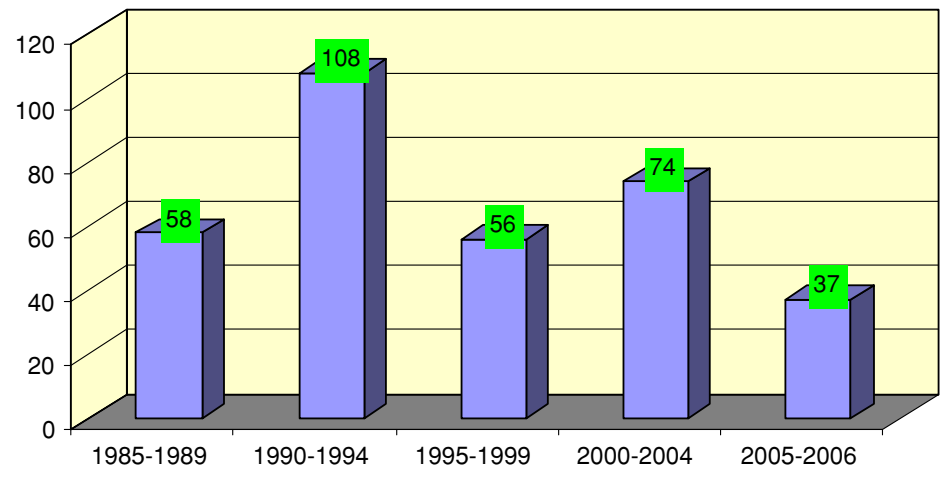

Fig. 1 PhDs in education at UP, 1985-2006

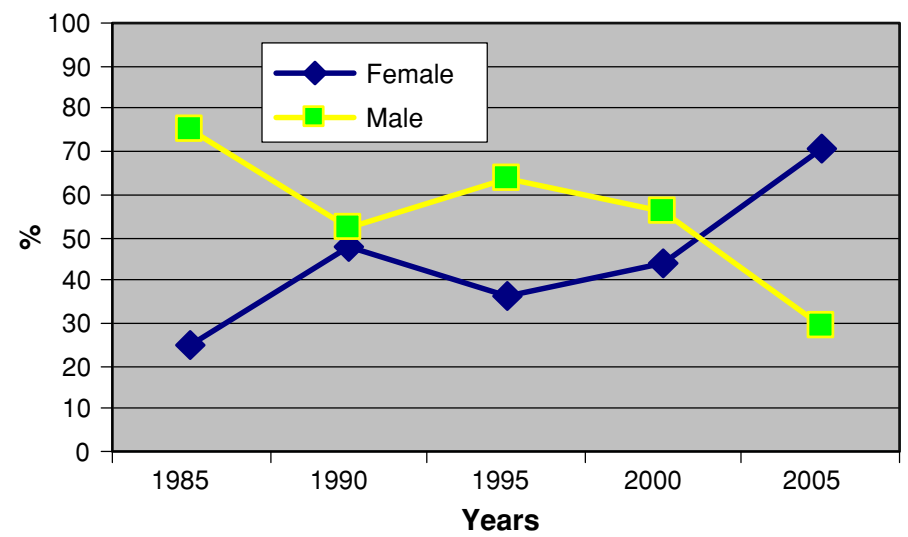

Fig. 2 PhDs by gender at UP, 1985-2005

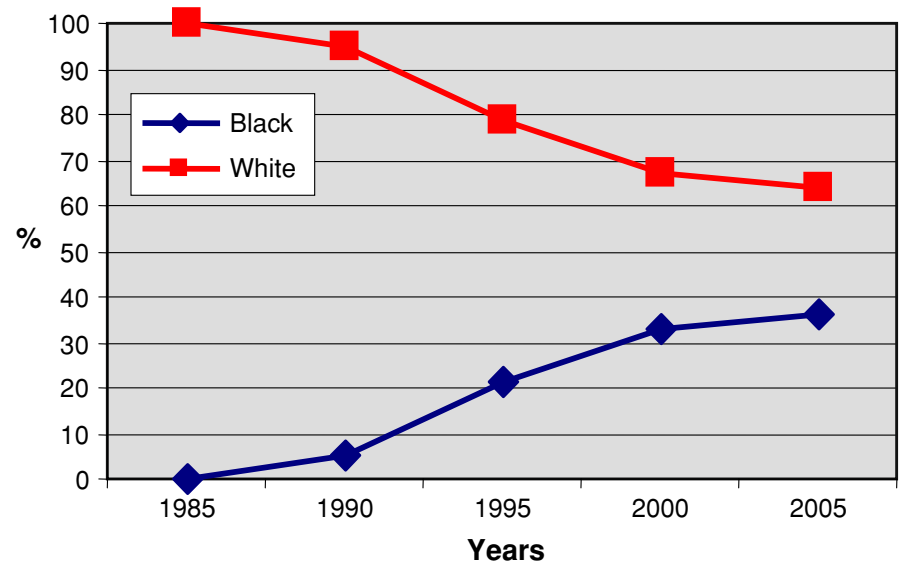

Fig. 3 PhDs by race at UP, 1985-2005 


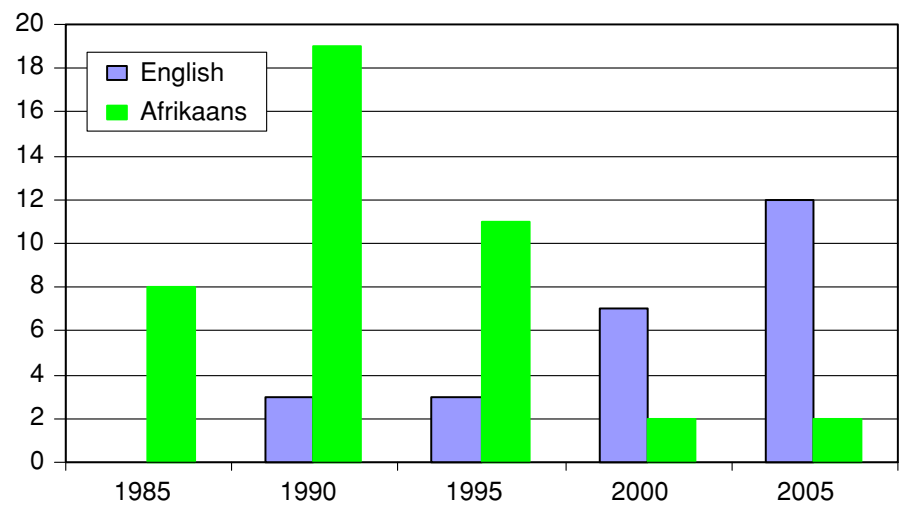

Fig. 4 PhD dissertations by language at UP, 1985-2005

Another dramatic shift took place in terms of language. As Fig. 4 indicates, English has become the preferred medium for dissertations. This not only reflects the diversity in terms of race but also, according to the interviewees, the fact that Afrikaans-speaking students prefer to write their dissertations in English.

\section{UP faculty of education: structure, governance and knowledge (1985-2005)}

As stated, the purpose of this paper is to draw links between the different epistemic environments and the epistemologies and methodologies employed at doctorate level, as well as to assess to what extent the struggle around knowledge production is reflected in the $\mathrm{PhD}$ dissertations.

The paper groups what counts as knowledge in doctoral research at UP into three distinct periods. In the first period, from 1985 to 1990, the authoritarian and regulated epistemic environment of the apartheid era created research fundamentalism, patronising and pseudo scientific knowledge. The demise of apartheid in 1994 unsettled the institution, but substantive change in the conception of knowledge and understanding of research did not take place. Therefore, in the second period, from 1995 to 2000, the doctoral dissertations produced disengaged knowledge that lacked critical discourse and relevance. A change in the epistemic environment began to take place in the third period, post-2000, and this had an impact on the PhDs awarded in 2005. In this period, knowledge became tentative and exploratory, yet it was constrained by the institution's long-established epistemic environment.

The aim of the following sections is to provide a short description of UP's Faculty of Education at each epistemic period and the way the departments were structured and restructured at that phase, bearing in mind that structural changes are also epistemic shifts (Bernstein 1971). Each section also explores the changing conceptions of knowledge at the faculty and the impact this has had on knowledge production at doctorate level by analysing the dissertations awarded during that time.

It is important to note three points. Firstly, that each graduation year represents the work done in the faculty in the years preceding the award of the degrees. Second, there is no attempt to benchmark the history of educational research at UP against international trends or even against other universities in South Africa. This paper compares UP to itself at 
different political periods. Finally, there is no attempt to comment on the quality of the work; the focus is on the graduates' conceptions of knowledge and how these relate to the institution's epistemic environment.

\section{'Scientific' and controlled knowledge: 1985-1990}

From its early beginnings, UP positioned itself as an Afrikaner institution whose basic task was to serve and protect Afrikaner ideals and culture (Mouton 2007). In order to achieve this goal it was governed in a strongly authoritarian way (Bunting 2002b). Jansen, reflecting on his experiences at the institution in 2000-2001, describes UP as an institution where decision-making is imposed from the centre, where no debate is encouraged and where 'intellectual authority vests in seniority rather [than] in the mix of personal talent in attendance' (2001, p. 2). Jansen further maintains that this authoritarianism has been reinforced by a culture of 'politeness' bordering on hypocrisy, in which there is a strong institutional aversion to conflict and disagreement (Jansen 2005).

In an interview conducted for this research, an academic in the faculty lamented that this aversion to debate is what happened to the Afrikaner under apartheid. She demonstrated the lost possibilities for Afrikaner intellectual debate by paraphrasing the Afrikaner poet N P van Wyk: 'We have lost the open discussion that I can differ from you, but in the end I can depart from you wiser but we can still be friends.'

Within this mindset, the Faculty of Education had a strong commitment to phenomenology, fundamental pedagogics and a Christian philosophy of life. Phenomenology was understood 'as the science which studies an appearance (phenomenon) as it manifests itself in the world' (Landman et al. 1982, p. 80). The role of the phenomenologist was to discover the authentic structure of the phenomenon by using a 'scientific method'. Pedagogics, or the theory of education, comprises various sub-disciplines such as psychopedagogics, socio-pedagogics and fundamental pedagogics, ${ }^{3}$ with the latter forming the epistemological grounding for all other sub-disciplines. In this epistemic environment, knowledge was conceptualised as fixed, certain, controllable and scientific. There was an understanding of truth as objective, and ideology was excluded, since all 'these "-isms" conceal the essence of the reality of education' (Landman et al. 1982, p. 82).

This approach was criticised as being a convenient way to avoid the critical sociological, economic and political issues that confronted South African education under apartheid. With this approach the 'essence' of certain areas of education was taught with little or no emphasis on the societal relations of education in South Africa (Weeks et al. 2006). The preferred research methodologies in the doctoral dissertations were theoretical text analysis, literature review and sometimes quantitative methods, mostly questionnaires. Bibliographies in the Afrikaans dissertations featured mostly Afrikaans texts. One academic succinctly described the isolation and the pressure to conform at the time:

There was an academic boycott.... There was major in-breeding. The circle was very small and you had to swim in it. If you don't swim in it you are out of the pond.

But even in that conservative climate there were some academics who thought differently, either because they had international exposure or because they were able to think 'out of the box'. These academics were, however, mostly marginalised in the faculty; not dissimilar to the experiences of academics in UP's history department, as vividly described

\footnotetext{
${ }^{3}$ Sometimes referred to as the philosophy of education.
} 
by Mouton (2007). Furthermore, according to one interviewee, these academics were not allowed to supervise any doctoral students-with the result that they could not qualify for promotion. Doctoral students were thus initiated into the methodological and epistemological hegemonic community of scholars.

The aims of the theses awarded in 1985 were usually to trace, describe or design programmes and theoretical models or to provide support for fundamental pedagogic concepts. An example of the latter is Meyer's (1985) dissertation where he writes enthusiastically at the end of the abstract: 'In this investigation the achievement of Fundamental Pedagogic structures within youth movements was found to be essential, otherwise there could be no notion of education.'

The Faculty of Education had a strong 'ivory tower' syndrome. Research was considered to be the business of 'experts' who studied the problems of others from a distance. Research knowledge was used to guide society and prescribe for it the 'right' way. This was clearly evident in orthopedagogics (psychology) which focused on correcting deviant behaviour and, especially, on guiding parents regarding child education. For example, Schalkwyk (1985) designs some pedotherapy plates that would correct the 'discordant dynamics of education, the dysfunctional education actions of the parent and the unfavorable meanings of the child'. Meintjes (1990) conducted three case studies of milieudeprived families in order to understand their pedagogical, psychological and social characteristics. This thesis refers to people who live 'in dire poverty with associated pathological phenomena, for example alcoholism, divorce, extra-marital relationships and child neglect', indicating a strong moralistic undertone and unquestioning assumptions between social class and social problems.

Two black students were awarded their doctorates at the faculty in 1990 . One thesis looks at the principles for the design of a culturally relevant instrument to identify gifted black secondary school children (Tlale 1990). The second studies vocational orientation as a value concern and recommends that 'the parent's share in the value orientation of his child should be expanded, vocational orientation should receive scientific and expert training on values, and a scientific accountable curriculum for vocational orientation which includes values should be introduced in the primary and secondary school' (Kunutu 1990). There is no reference to political or social contexts. In this example, as in many others, research is used for advocacy; knowledge is passed off as 'scientific'.

These dissertations by black graduates exemplify Jansen's (2009) claim that even though UP opened its doors to black academics in the early 1990s, they were usually blacks who "bore the ideological and epistemological birthmarks of their trainers ... and who achieved their degrees and their junior level posts within white universities precisely because they "fit in" ...' (187).

A particular way of conceptualising social issues is also evident in the motif of 'harmony' which is common to a number of dissertations. For example: Vorster (1990) describes the child with learning disabilities as one who is living in a disharmonious relationship with his/her environment; Meintjes (1990) claims that disharmonious parentchild interaction is realised in the milieu-deprived family; Willemese (1990) establishes that 'disharmonic education results in a child with flaws in his personality, which leaves him susceptible to drug abuse'. Another dissertation studies the link between 'prosperity and disharmonious education' (Bodenstein 1990).

One academic explains the motif of harmony in relation to the Christian underpinning of UP and the religious desire that all be in harmony: the individual, family, and social institutions such as schools and church. Another academic explains this motif as part of the epistemic environment of the education faculty: 
Harmonious: if you are not with us you are against us - all need to be in harmony. Why was I an outsider? I was in disharmony. I did not fit in with the normal way of thinking.

The abstracts do not mention methodology and the topic receives scant attention in the dissertations, usually one to two pages. The dissertations mostly comprise a philosophical analysis of educational texts with no empirical work involved. An example of a practical topic which received a pure philosophical analysis is Beckmann's (1985) thesis, titled 'A triadical-hermeneutical analysis of pedagogically accountable co-operation between parent, teacher and child'.

Phenomenology was uncritically accepted as both epistemology and a methodology. One of the 1985 graduates explains:

What was attractive about that was that they pretended to be able to guide you to a thing called objective truth-they have the recipe and the answer. The point of departure was that you could find an objective truth provided that you have the mechanism, the methodology to allow the phenomenon to reveal itself to you, as it could speak to you. We did not discuss any other kind of methodology ... There were two books that were circulated among the students: De Wet from Potchefstroom, ${ }^{4}$ and this was more for quantitative, and Landman ${ }^{5} \&$ Gouws.

The same interviewee also describes the process of doing a doctoral thesis as highly controlled by the supervisor:

My supervisor came to me. I would say I want to work on something and he came to me and he had the whole table of contents worked out and I had to try and fill it in.

Most of the dissertations have a similar structure: the introductory chapter usually includes a dictionary translation of the key words used in the dissertation into English, French and Latin. This concern with the etymology of words is related to the phenomenological desire to unravel the essence of the concept. In most cases this is followed by an explanation of the phenomenological, dialectic, hermeneutical or triadic methods.

It is evident that the conformity and order gave the institution control over knowledge. According to one academic, this was the influence of W A Landman, who was head of the Fundamental Pedagogics department at the Faculty of Education from 1968 to 1989:

Landman gave research workshops in which he provided the students with research structure to do their PhDs. While students were encouraged to use phenomenology, there was no engagement in the philosophical foundation of this approach. The chapter on phenomenology stayed all by itself to show that you have come across these concepts and you can write them. It was not carried through into the dissertation. The link, the integration of what you write in the first two chapters with the actual research was not important.

By 1990 a few dissertations begin to refer to either qualitative or quantitative approaches or to a specific method such as survey, longitudinal study, questionnaire or observation. Context is usually ignored. But still the structure of the dissertation to a large extent continues to be prescribed by Prof. Landman, a practice which is openly described in Combrinck's (1990) dissertation on technical education:

\footnotetext{
4 Another Afrikaans-medium university in South Africa.

5 Head of Fundamental Pedagogics, University of Pretoria 1968-1989.
} 
The historical development of technical education is described with reference to a methodological analysis of relevant documents on the basis of the historical phenomenological method of Johnson as refined in terms of research procedures by Landman.

\section{Disengaged knowledge: 1995-2000}

In the early 1990s, with the imminent political change and the growing exposure to international knowledge, the Faculty of Education made some name changes but could not embrace a methodological and epistemological shift to a new research culture. According to a respondent:

The Department Fundamental Pedagogics changed to the Department of Fundamental Pedagogics and Education Management and Historical Pedagogics in $1992^{6}$ - at that stage it became clear to people that there are questions about phenomenology and Fundamental Pedagogics. Gradually there was the settling in of an awareness that you cannot play with the notion of 'objective truth'. People started to encourage creative methods in research; let's start looking at other approaches. But that took some time to cement itself ...

It was evident that while individual academics were ready for the shift, the institution was lagging behind:

When a board member heard ... that we [were] starting [to] think differently about what we [were] doing, we were called in ... [and told]: 'In this faculty... we don't use terminology such as facilitation of learning, such as paradigm shift, such as postmodernism' ... That was in 1992-1993. During that time [Prof.] and I decided that we drastically needed to re-change, transform and reform ... I was actually stopped from doing it ... because it gave confidence to the students to ask questions.

Consequently, while the 1995 graduates was studying toward their doctoral degrees, the approaching new social order in South Africa had very little impact on their epistemologies or methodologies. The dissertations that were completed in 1995 continued to be decontextualised, disengaged and providing models and guidelines to a society that no longer existed.

Almost half the doctorates in 1995 were awarded in Orthopedagogics, with a strong focus on testing, especially for school readiness (Badenhorst 1995; Van Rooyen 1995). Other topics included the influence of television on the sex education of the early adolescent (Louw 1995) and a proposed model for South Africa for the admission of children with learning disabilities (Theron 1995). The aim of abolishing a disharmonic educational dynamic by providing guidelines for parent values education continues in Jacobs's (1995) dissertation.

In 2000, 6 years after the transition to democracy, doctoral dissertations continued to offer intervention programmes, guidelines and models in different areas, while accommodating the new educational context in South Africa. For example: Maake (2000) proposes an interactive television model for service education and training guidance in rural areas; Moore (2000) proposes a model for Recognition of Prior Learning for Adult Basic

\footnotetext{
${ }^{6}$ It was later named the Department of Education Management and was changed again to Department of Education Management and Policy Studies.
} 
Education and Training; Van Loggerenberg (2000) designs a model for training teachers for an outcomes-based technology curriculum; De Jongh (2000) designs diagnostic English reading materials for the heterogeneous population of South African learners in grades 13; and Hartell (2000) considers what a family education programme should look like since '(t)echnological, industrial and economic development led to parents often not fulfilling their responsibilities to bring up their children adequately'. In this abstract the old epistemic environment and the view of society as deviant is still evident as the graduate attempts to make space for the new education policy in South Africa and specifically outcomes-based education:

The study undertook situation analysis to identify family pathologies and dysfunctionings, and by comparing it to the international programme of family education, the study develops a programme for family education in schools in accordance with Outcome-based [sic] education.

Black $\mathrm{PhD}$ students continued to be integrated into the institutional thinking and produced dissertations with a strong didactic tone. One graduate from the Department of School Guidance investigated why most pupils from the Swazi region do not find work after completing their matric year. The study recommends a model for upgrading the guidance programme but lacks reference to the political and social context (Mkhatshwa 1995).

Another dissertation attempted to explore ideological influences on state education in Lebowa and especially what caused deterioration in education output as measured in terms of Standard 10 results (Petje 1995). It is evident that the distinction between ideology and 'scientific' research was not explored. The researcher argues that 'there is no clear distinction between scientific statements of facts and ideological statements of values' in educational research and that even when ideology is inevitable its reality 'remains to be discovered through unrelenting scientific research'.

'Through scientific investigation', Petje comes to conclusion that 'criticism could be leveled at all stakeholders ... for not playing their roles' and that schools were used by 'political organisations to wage a struggle against the state [and] thus education suffered'. It is ironic that a black researcher was unable to unravel the complexities of schooling in a black area at the time of the transition to democracy.

The influence of phenomenology and fundamental pedagogics was still evident. One study undertook an analysis of the phenomenon of morality from a philosophical point of view and its application to education, combined with a situational analysis of morality in South Africa. The researcher comes to the conclusion that the "educand in his path of becoming a morally independent adult, has a tangible need for morality education in particular' (Hendrikz 1995).

While there are still some abstracts that do not refer to method or research question, a greater variety of methods have been used, such as interviews, questionnaires, case studies, surveys and statistical analysis as well as phenomenological text analysis. Yet it seems that even when new qualitative methods were incorporated, they were not accompanied by reflection and were not linked to a new conception of knowledge. Consequently, $\mathrm{PhD}$ students could use interviews to explore other stakeholders' points of views, inadvertently forwarding a notion of 'truth as subjective' or 'constructed', at the same time that they would declare that the study employed the phenomenological approach, which allowed the researcher to observe the phenomenon accurately and objectively by discovering and disclosing 'all things that may cloud the phenomenon from revealing itself in reality' (Mkhatshwa 1995). 
That phenomenology was still considered the 'right way' can be gleaned from Petje's (1995) assertion that: 'Since the study is pursued in the field of Philosophy of Education, [a] phenomenological approach cannot be dispensed with.' His references for the methodology chapter include Landman and Gouws's 1969 book Fundamental Pedagogics. The reference to Landman book in this example is an indication of the fossilised and unchanging research culture.

Maile (2000) avoids using the language of phenomenology explicitly and includes qualitative methods in his dissertation. But a close reading of the abstract and the methodology chapter shows traces of the old phenomenology thinking. Maile refers in his abstract to his desire to unravel the real situation. In the following quotation from his methodology chapter, phenomenological thinking is evident in his reliance on text analysis and etymology of words (hence the use of dictionaries) and the authority of the supervisor:

The methods used are literature study and empirical investigation .... The internal validity of the research subject will be based on literature that is available and catalogued in the bibliography. Primary sources such as education laws, letters, circulars, reports, magazines, journals, newspapers, and dissertations will be used. The researcher will also collect data from tertiary sources such as dictionaries and encyclopaedias. Secondary sources will also be used. Crucial facts will be drawn from my supervisor (Maile 2000, p. 10).

It seems that while there was a growing awareness of context and increased reference to interviews and questionnaires, there was no substantive change in the conception of knowledge and the phenomenological framework was still employed in some dissertations. The methodology chapters to a large extent continued to include the etymological-semantic meanings of the words and an explanation of the phenomenological, triadic and hermeneutic methods. The knowledge that was produced was mostly detached from the changing South African context.

\section{Exploring knowledge: 2005}

The tentative and often institutionally challenged steps toward a new conception of knowledge towards the end of the 1990s, received a strong push with the arrival of the new dean in 2000. In his reflections on his attempts to change the authoritative and patriarchal environment to one of openness, participation and engagement, Jansen traces a difficult and emotional process of transformation, strewn with dilemmas, uncertainties, successes and failures (Jansen 2005, 2009).

Jansen spearheaded a strong initiative to confront the institution's epistemic environment. Academics and doctoral students were introduced to local and international scholars who challenged their traditional way of thinking. Department names were changed to indicate a shift away from disciplinary thinking and from the notions of pedagogics and didactics. For example, the Department of Orthopedagogics became the Department of Education Psychology, the Department of Psycho and Sociopedagogics was renamed the Department of Educational Studies, and Didactics became teacher training. The new names gave a clear signal that 'we, with the rest of the intellectual world, are not stuck in 1950'.

Resources were mobilised to send academics to conferences or to overseas universities for extended periods. The conception of knowledge as constructed, tentative and contextualised was advanced, as opposed to the positivist, elitist notion of knowledge as 'scientific' and 'objective'. This required fundamental change in the epistemic environment. 
Academic women were advanced in a male-dominated institution. ${ }^{7}$ New academics were brought in from outside the political and epistemological world of the Faculty of Education. Some of them began to provide the intellectual leadership for the faculty, while the 'old guard' who did not fit in left or were confined to administrative roles. This brought about feelings of disempowerment and resentment as a number of academics overtly or covertly resisted the change (Jansen 2009). The impact on the epistemic environment was immense as evident from the following excerpts from interviews with academics in the faculty:

I came from a quantitative background and was introduced to qualitative research by Prof. Jansen. I realised that you don't have to do stats of numbers and percentages to compare and correlate. The personal voice that he allowed us to use just opened up a whole new world for me ...

We were fond of building models ... which ended in nothing because these models were never tested in practice, never operationalised, never went beyond that to the next step. People realise that research needs to intervene in practice. Prof. Jansen made us aware of that.

Readings of the 2005 abstracts reflect a change in the epistemic environment under the leadership of Jansen, and the tension that this change created for a number of graduates and their supervisors. It is evident that in the institutional environment that allowed for epistemological and methodological diversity, the two conceptions of knowledge co-existed, sometimes complementing and sometimes contradicting each other.

Perhaps the most important shift can be detected in the way that the elitism and pseudophilosophical stance that characterised the previous periods had slowly given way to a different notion of research. It seems to have become understood that the research role is not to offer solutions or theoretical models but to explore and understand. Further, it has become understood that truth is not objective and that the essence of social phenomena cannot be revealed scientifically but is complex and needs to be explored. The dissertations aim at exploring how the participants construct their own meaning. For example, Maguvhe (2005), a blind PhD student, investigates how learning is facilitated in special schools for blind learners; and Rogan (2005) explores how pre-service educators develop their sense of professional efficacy.

In educational psychology, quantitative testing continued (Hefer 2005) beside a qualitative study that explores the experiences of children growing up in same-gendered families (Lubbe 2005). Lubbe looks at the 'other' not as the deviant part of society that needs to be corrected but as an integral part of the 'heteronormativity of society'. Du Plessis (2005) studies the academic self-concept of students with hearing impairment in the contexts of special and full-service inclusion schools. It seems that education psychology is making the shift towards assessing learners in the context of school and hearing 'their own meaning making'.

The tension between the old conception of knowledge and the new could be exemplified in the emphasis that white Afrikaans universities had on 'education law' and 'education management' versus the English universities' tendency towards 'education policy' and 'education leadership'. One of the respondents points to the different mindsets:

You might want to ask why there is still a Department of Education Management [at UP] where every other place in the world talks about leadership. Why is it that we

7 All heads of department until 2000 were male (Ad Destinatum 1983-1992; Ad Destinatum 1993-2000). 
have education law while not a single other university has education law? Why? Because this university was tied up for many decades with the government and government bureaucracy, there must be education legislation. The English universities were out of the system so it had to be in the Afrikaans universities.

While policy issues such as quality assurance (Zitha 2005) or the meaning of the concept of access to education (Gamede 2005) became the topics of investigation, Van Vollenhoven (2005) tries to accommodate both 'education law' and 'education policy' in his dissertation. His historical association with education law was challenged by the dean, but he could not do a complete shift to policy thinking. As a result, his thesis has the traditional law structure and looks at different legislative frameworks while at the same time exploring learners' understanding of the law and their rights, and the factors that facilitate or inhibit the implementation of their rights. In order to complete his dissertation, Van Vollenhoven needed two different supervisors representing two different conceptions of knowledge. His dissertation thus comprises two chapters on conceptual framework, one based in the law discipline and one based in the interpretive framework. Although attempting to straddle law and policy, one can discern a tension in that he is not sure where to locate himself:

It is fascinating. But now I am not sure if I can publish in a real law journal, because I think that they don't want empirical, qualitative research, they want the legal stuff.

The abstracts begin to employ new buzz words, referring to research as an intellectual puzzle', as having a conceptual or theoretical framework. There is a growing awareness that the dissertation needs to contribute to current dialogue in education. To a certain extent it is a period of methodological experimentation, especially in qualitative research. While most studies used interviews, focus groups or case studies, other methodologies were also used, such as action research (Voges 2005) and narrative analysis (Rogan 2005; Lubbe 2005). However, some dissertations still used the familiar combination of literature review and questionnaire as their methodology, without any attempt to deal with the epistemological implication of their choices (Mahlangu 2005). Some academics underwent a process of deep change, while for others who remained steeped in the old conception of knowledge, it meant only a superficial rhetorical shift:

Most of the ... people started to take on the language of progressive methodology like discourse analysis, postmodernism narrative-but they only took on the form, not the substance. [...]'s thesis was an exception. She understood that when one takes narrative discourse to its logical conclusion, then it is self reflective, it is challenging, destabilising. So even when some of her colleagues had this fanciful dropping out of progressive language, it had not seeped down into the political; for her it did.

It is evident that the new epistemic environment created 'epistemic confusion' for some academics who, in order to survive in a different intellectual world, had to adapt different terminology while remaining loyal to their traditional epistemic environment. One academic who graduated in 2000 defended the methodology used in his dissertation. While, admittedly, he no longer uses this approach with his doctoral students, he still sees knowledge as scientific and still longs for the prescribed structure provided by the discipline. It seems that the respondent does not acknowledge the extent to which the theoretical framework impacts on the data and its analysis but sees it as a simple 'add on':

The methodology was prescribed within the field that you worked in. This was how we worked in history. ... We don't use it anymore. I don't see anything wrong in this 
approach; we only need to bring in the theoretical framework that we didn't bring in before. But there is nothing wrong, it is logical. It also helps you to analyse your data, chronologically or thematically. You look at the phenomenon. I think that the approach of the history of education, depending on the study that the pupil is using, it is a good scientific approach...

The choice of presenting a model as the aim of research and the elitist view of university as providing guidelines for society is also defended by the graduate:

We can't just go to the schools. You need to have this analysis first. These recommendations are scientifically researched. This is what society really needs. So now we can try it in the field. But this is a different research.

It seems that even though the institution opened up to qualitative research, some academics have not shifted away from a 'scientific' approach to knowledge and the dominance of the positivist, quantitative approach:

In the past when we were subjected to fundamental pedagogics we were told to [stay] objective. But with a lot of change taking place, the impact of society is much greater and this has changed the perception of many people, which is why we have qualitative research. My recent work has a good mix of quantitative and even more qualitative work, yet ... I still like to see some quantification within the coding and the classification of certain categories and observations. It might be my positivist natural science trend. Let's have a look at your transcription ... let's code the phenomenon, let's see where the commonality is. So what we have here is much [more] of a logical way to go about doing things. Where originally we did factor analysis quantitatively I am now doing it by hand. I now count it. OK these are [some] people's ideas but how many people have similar opinions ...

Another 2005 graduate-who, according to her, has become 'comfortable with qualitative research'-is also continuing to incorporate a great deal of quantitative research in her work with doctoral students and in her own research. While there is a definite place for both qualitative and quantitative data in education research, the issue here is not the quantitative-qualitative debate but rather the reason that this graduate and the other respondents emphasise for using quantitative research. It is evident that the institution's traditional epistemic environment has a major impact on this respondent choice:

It [quantitative] is an easy form of data collection. Also it is a traditional way of collecting data. That's what people knew. People believe that if you are doing research you need to have data. It is a perception that you have to have data. Quantity, correlate, make nice graphs. I am a graduate of Tukkies [UP]. It is a mind set.

This mind set was a challenge that brought Jansen to the conclusion that changing the epistemic environment is constrained by decades of epistemological fundamentalism and by the 'knowledge in the blood', that is, knowledge that is 'embedded in the emotional, psychic, spiritual, social, economic, political, and psychological lives of a community' (Jansen 2009, p. 171). In an interview Jansen elaborates:

It is precisely the pretence of science or scientific that was the problem because there was a political agenda behind that ... In meetings people would talk about knowledge being managed, knowledge as being accountable, knowledge being measurable, 
knowledge being above ideology ... All this did not go away in spite of doing a number of things to change this thinking ...

It seems that even strong drivers for change, such as political transformation and agency, are inhibited by the institution epistemic environment.

\section{Conclusions}

The aim of this paper is to investigate the relation between social change, epistemologies and methodologies at doctoral level. For this aim the year 1994 was chosen as an external marker to assess changes in the conception of knowledge before and after the transition to democracy in South Africa. It seems that this external marker had very little relevance to the epistemic environment at UP's Faculty of Education. It is quite remarkable that what was considered worldwide as a 'miraculous' transition to democracy in 1994 was unable to change substantially the stultifying research culture at the faculty, and that change was mostly semantic, if at all. Yet perhaps it is not surprising that the political transformation had little effect on research culture in an institution which managed for a number of decades to ignore societal and political issues. ${ }^{8}$

The analysis of the dissertations that were awarded between 1985 and 1990 shows understanding of knowledge as positivist, scientific and objective. The research topics and methodologies were determined by the philosophy of Fundamental Pedagogics and excluded issues and analyses that might challenge the apartheid regime. The research was produced in a regulated and authoritative epistemic environment whereby critical debate was discouraged and predetermined structures controlled what was considered as knowledge. The institutional control and the methodological hegemony established a single and uncritical conception of truth. It produced pseudo-philosophical knowledge, or rather ideology masquerade as science, with little relevance to the society which it aspired to correct. Exceptions were few.

The collapse of the apartheid regime undermined these conceptions of truth and knowledge. However, with the lack of an alternative understanding of knowledge, the PhDs from 1995 to 2000 produced research that was detached and disengaged from the educational reality in South Africa. Theoretical models, with no practical application, took the place of the scientific truth. Individual attempts at transformational research were frustrated by the institutional epistemic environment and the authoritative, paternal faculty management. Yet the broader political transformation created the conditions that eventually opened the doors of the faculty to new academics who brought in transformative ideas.

A new research culture began to shape the doctoral dissertations in the post-2000 period as a result of the 'epistemic attack' waged almost single-handedly by the new black dean. As the institution became more democratic and diverse, it was exposed to different ways of thinking and governance. Subsequently, significant changes took place in the way knowledge was presented at doctorate level. There was a momentous shift from epistemological and methodological fundamentalism to epistemological pluralism, from controlled to flexible methodology. The most noticeable changes occurred in a new understanding of society, not as deviant and dysfunctional but as complex and diverse. Research shifted from the archives and laboratories to the context of application; its aim became to find meanings and to understand complex situations instead of building models

${ }^{8}$ For a deeper and insightful analysis of the UP transformation see Jansen 2009. 
and providing guidelines. Various research methods, both qualitative and quantitative, increasingly replaced the long-established methods of phenomenology and literature review. Understanding of knowledge as tentative, exploratory and fluid prevails. Yet it is evident that even transformational change has its limitations and that a substantive shift toward a new conception of knowledge has been frustrated by methodological and epistemological conservatism as UP's habitual epistemic environment lingers on.

Jansen maintains that 'if transformation [is] going to happen at all, it would have to happen at the level of knowledge' (2009, p. 20) and at institution level. Doctoral students, as the producers and carriers of knowledge, could lead this transformation if change would come from within. It is a slow process that will not happen in a restrictive and authoritative epistemic environment. As this paper clearly demonstrates, knowledge transformation began to take place within democratic and less formal institutional arrangements which facilitated epistemological and methodological experimentation.

\section{References}

Badat, S. (2008). The trajectory, dynamics, determinants and nature of institutional change in post-1994 South Africa Higher Education. Conference paper presented at Higher Education Close Up 4, University of Cape Town, Breakwater Conference Centre, 26-28 June.

Badenhorst, F. H. (1995). Qualitative-quantitative analysis of the intellectual abilities of the deaf (In Afrikaans). Pretoria: Orthopedagogicsm, Faculty of Education. PhD.

Beckmann, J. L. (1985). A triadical hermeneutical analysis of pedagogically justified co-operation between parent, teacher and child (In Afrikaans). Pretoria: Fundamental Pedagogics. D Ed.

Bernstein, B. (1971). On the classification and framing of educational knowledge. In M. Young (Ed.), Knowledge and control: New directions for the sociology of education (pp. 47-69). London: Collier Macmillan Publishers.

Bodenstein, A. M. (1990). Prosperity and disharmonic education (In Afrikaans). Pretoria: Orthopedagogics, Faculty of Education. D Ed.

Bunting, I. (2002a). Funding. In N. Cloete, R. Fehnel, \& P. Maassen et al. (Eds.), Transformation in higher education: Global pressures and local realities (pp. 115-146). Cape Town: Centre for Higher Education (CHET).

Bunting, I. (2002b). The higher education landscape under apartheid. In N. Cloete, R. Fehnel, \& P. Maassen et al. (Eds.), Transformation in higher education: Global pressures and local realities (pp. 58-86). Cape Town: Centre for higher education (CHET).

Combrink, G. P. (1990). Teaching of technics: A multiple perspective analysis (In Afrikaans). Pretoria: Fundamental Pedagogics, Faculty of Education. PhD.

Cornwall, A., \& Brock, K. (2005). What do buzzwords do for development policy? A critical look at "participation", "empowerment" and "poverty reduction". Third World Quarterly, 26(7), 1043-1060. doi: $10.1080 / 01436590500235603$.

De Jongh, A. J. (2000). The design of a diagnostic reading materials for South African learners in the foundation phase using English as the language of learning. Pretoria: Education Psychology, Faculty of Education. PhD.

Du Plessis, A. B. (2005). The academic self-concept of learners with hearing impairment in two South African public school contexts: Special and full-service inclusion schools (In Afrikaans). Pretoria: Education Psychology, Faculty of Education. PhD.

Gamede, T. (2005). The biography of access as an expression of human rights in South African education policies. Pretoria: Education Management and Policy Studies, Faculty of Education. D Ed.

Hartell, C. G. (2000). An historical educational study of family education in schools (In Afrikaans). Pretoria: Socio Pedagogics, Faculty of Education. PhD.

Hefer, E. (2005). The early identification of neuropsychological learning disabilities in grade 1 learners (In Afrikaans). Pretoria: Education Psychology, Faculty of Education. PhD.

Hendrikz, W. A. (1995). Views from a number of morality philosophers and their meaning for education (In Afrikaans). Pretoria: Psycho and Socio Pedagogics, Faculty of Education. PhD.

Jacobs, A. H. (1995). Value orientation in parental guidance and pedotherapy. Pretoria: Education Psychology, Faculty of Education. $\mathrm{PhD}$. 
Jansen, J. D. (2001). Why Tukkies cannot develop intellectuals (and what to do about it). Innovation lecture series, University of Pretoria.

Jansen, J. D. (2005). Black dean: Race, reconciliation and emotions of deanship. Harvard Educational Review, 75(3), 306-326.

Jansen, J. D. (2009). Knowledge in the blood: Confronting race and the apartheid past. California: Stanford University Press.

Jansen, J. D., Herman, C., et al. (2007). Tracing and explaining change in higher education: The South African case. Review of higher education in Souh Africa. Pretoria: Council on Higher Education.

Karmon, A. (2007). "Institutional organisation of knowledge": The missing link in educational discourse. Teachers College Record, 109(3), 603-634.

Kunutu, P. (1990). Vocational orientation as a value concern. Pretoria: School Counselling, Faculty of Education. PhD.

Landman, W. A., \& Kilian, C. J. G., et al. (1982). An introductory reader in fundamental pedagogics for the student and the teacher. Cape Town: Juta \& CO, Ltd.

Louw, C. D. (1995). The effect of television on the sex education of the early adolescent (In Afrikaans). Pretoria: Orthopedagogics, Faculty of Education. PhD.

Lubbe, C. (2005). The experiences of children growing up in same-gendered families. Pretoria: Education Psychology, Faculty of Education. PhD.

Maake, M. J. (2000). Using interactive television in the in-service education and training of guidance teachers. Pretoria: Education Guidance and Counselling, Faculty of Education. D Ed.

Maguvhe, M. O. (2005). A study of inclusive education and its effects on the teaching of biology to visually impaired learners. Pretoria: Curriculum Studies, Faculty of Education. $\mathrm{PhD}$.

Mahlangu, V. P. (2005). The relationship between the school principal and the school governing body. Pretoria: Education Management and Policy Studies, Faculty of Education. PhD.

Maile, S. (2000). Recognition of competence: An empowerment model for the retention of excellent teachers in the classroom. Pretoria: Education Management, and Policy Studies, Faculty of Education. PhD.

Meintjes, B. J. J. (1990). Pedagogical, psychological and social characteristics of milieu-deprived family. Pretoria: Psycho and Socio-Pedagogics, Faculty of Education. PhD.

Meyer, F. (1985). The relevance of fundamental pedagogical structures in planning the activities of a youth society (In Afrikaans). Pretoria: Fundamental Pedagogics. Faculty of Education. D Ed.

Middleton, S. (2001). Educating researchers: New Zealand education PhD 1948-1998 ('State of the Art' Monograph, No. 7). Palmerston North: New Zealand Association for Research in Education.

Mkhatshwa, T. A. (1995). A training model for school councellors in the Swazi region of the Eastern Transvaal province. Pretoria: School Guidance, Faculty of Education. PhD.

Moore, A. (2000). Recognition of prior learning in a contemporary South African context: A non-formal education approach. Pretoria: Psycho and Socio Pedagogics, Faculty of Education. PhD.

Mouton, F. A. (Ed.). (2007). History, historians and Afrikaner nationalism. Essays on the history department of the University of Pretoria 1909-1985. Vanderbijlpark: Kleio.

Muller, J. (2003). Knowledge and the limits of institutional restructuring: The case of South African higher education. Journal of Education, 30, 101-126.

Petje, M. E. (1995). Ideological influences on state education in Lebowa. Pretoria: Education Philosophy. $\mathrm{PhD}$.

Rogan, A. (2005). Negotiating a path to professional efficacy: A narrative analysis of the experiences of four pre-service educators. Pretoria: Curriculum Studies, Faculty of Education. PhD.

Schalkwyk, S. J. J. V. (1985). Die ontwerp van enkele pedoterapieplate ter implemetering by indirektiewe pedoterapie (The design of some pedotherapy plates to implement with indirect pedotherapy). Pretoria: Faculty of Education, University of Pretoria. D Ed.

Theron, C. D. (1995). A reconsideration of the current provision of education for children with specific learning problems by the department of education and culture (administration house of assembly) (In Afrikaans). Pretoria: Orthopedagogics, Faculty of Education. PhD.

Tlale, C. (1990). Principles for the design of a culturally relevant instrument to identify gifted black secondary school children didactical pedagogics and subject didactics. Pretoria: Faculty of Education. PhD.

Van Loggerenberg, A. (2000). Implementing a problem-based learning model in the training of teachers for an outcomes-based technology curriculum. Pretoria: Department of Teaching and Training Studies. PhD.

Van Rooyen, A. E. (1995). The effectivity of some tests for school readiness for the prediction of scholastic achievement by the school beginner (In Afrikaans). Pretoria: Education Psychology, Faculty of Education. $\mathrm{PhD}$.

Van Vollenhoven, W. J. (2005). Learners' understanding of their right to freedom of expression in South Africa. Pretoria: Education Management and Policy Studies, Faculty of Education. PhD. 
Voges, A. (2005). An evaluative analysis of a whole brain learning programme for adults. Pretoria: Curriculum Studies, Faculty of Education. D Ed.

Vorster, O. W. (1990). Effective parenthood with reference to the retarded child (In Afrikaans). Pretoria: Orthopedagogics, Faculty of Education. PhD.

Weeks, S., Herman, H., et al. (2006). SACHES and comparative, international and developmental education in Southern Africa: The challenges and future prospect. Southern Africa Review of Education, 12(2), $5-20$.

Willemse, H. (1990). Drug abuse among adolescents in an urban environment (In Afrikaans). Pretoria: Orthopedagogics, Faculty of Education. D Ed.

Zitha, E. V. (2005). Quality assurance with special reference to adult literacy: A case study of education and training in business. Pretoria: Education Management and Policy Studies, Faculty of Education. $\mathrm{PhD}$. 